\title{
The second best arterial graft: A propensity analysis of the radial artery versus the free right internal thoracic artery to bypass the circumflex coronary artery
}

\author{
Robert F. Tranbaugh, MD, ${ }^{a}$ Kamellia R. Dimitrova, MD, ${ }^{a}$ David J. Lucido, PhD, ${ }^{b}$ Darryl M. Hoffman, MD, ${ }^{a}$ \\ Gabriela R. Dincheva, BS, ${ }^{a}$ Charles M. Geller, MD, ${ }^{a}$ Sandhya K. Balaram, MD, PhD, ${ }^{\mathrm{c}}$ Wilson Ko, MD,${ }^{\mathrm{a}}$ and \\ Daniel G. Swistel, MD
}

\begin{abstract}
Objective: We sought to determine if the radial artery (RA) or the free right internal thoracic artery (RITA) is the better conduit to bypass the circumflex coronary artery during coronary artery bypass grafting $(\mathrm{CABG})$ using the left internal thoracic artery (LITA).
\end{abstract}

\begin{abstract}
Methods: Propensity matching was performed on 2488 CABG-LITA patients from 2 affiliated centers, resulting in 528 pairs who received either a RA at one center or a free RITA at the other center to bypass the circumflex coronary artery from 1995 to 2009.

Results: Kaplan Meier estimated 1-, 5-, 10-, and 15-year survival rates were 99\%, 95\%, 85\%, and 76\% for RA patients, respectively, and $97 \%, 92 \%, 80 \%$, and $71 \%$ for RITA patients, respectively $(P=.060)$. Major adverse events (MAEs) were fewer in the RA group $(7.6 \%$ vs $14.0 \% ; P=.001)$ and use of the RA was a significant predictor of reduced MAEs (odds ratio [OR], 0.48; $P=.002)$ in all patients and especially in diabetic (OR, $0.32 ; P=.003)$, older (OR, $0.40 ; P=.009)$, obese (OR, $0.15 ; P<.001)$, and chronic obstructive pulmonary disease (COPD) (OR, $0.05 ; P=.016)$ patients. However, survival was better with RA only in COPD (hazard ratio, $0.49 ; P=.045$ ) and older (hazard ratio, $0.71 ; P=.050$ ) patients. Overall RA patency $(83.9 \%$ ) was similar to RITA patency $(87.4 \%)$ at a mean of $5.1 \pm 3.8$ years $(P=.155)$.
\end{abstract}

Conclusions: Long-term survival is similar in CABG-LITA patients using either a RA or free RITA graft to bypass the circumflex coronary artery. RA grafting has fewer MAEs, a similar patency to RITA, and improves survival in older and COPD patients. The choice of the second arterial conduit should be guided by patient profiles and surgeon preferences. (J Thorac Cardiovasc Surg 2014;147:133-42)

The addition of a second arterial conduit improves long-term survival after coronary artery bypass grafting (CABG) using the left internal thoracic artery (LITA). Numerous studies ${ }^{1-4}$ have shown a clear survival advantage of adding a right internal thoracic artery (RITA) compared with using the saphenous vein (SV). Similarly, multiple studies $^{5-8}$ have shown that the radial artery (RA) also has a strong survival benefit compared with SV grafting. Given the limitations of SV grafting, multiple arterial grafting is thus the increasingly recognized and recommended optimal treatment of multivessel coronary artery disease. ${ }^{9}$

\footnotetext{
From the Division of Cardiothoracic Surgery, ${ }^{a}$ Office of Grants and Research Administration, ${ }^{\text {b }}$ Beth Israel Medical Center, New York, NY; Division of Cardiothoracic Surgery, ${ }^{\mathrm{c}}$ St. Luke's Roosevelt Hospital Center, New York, NY. This work was supported by Division of Cardiothoracic Surgery divisional funds. Disclosures: Authors have nothing to disclose with regard to commercial support. Read at the 93rd Annual Meeting of The American Association for Thoracic Surgery, Minneapolis, Minnesota, May 4-8, 2013.

Received for publication April 9, 2013; revisions received July 30, 2013; accepted for publication Aug 20, 2013; available ahead of print Oct 7, 2013.

Address for reprints: Robert F. Tranbaugh, MD, Division of Cardiothoracic Surgery, Beth Israel Medical Center, 317 East 17th St, 11th Floor, New York, NY 10003 (E-mail: rtranbau@chpnet.org). $0022-5223 / \$ 36.00$

Copyright $(2014$ by The American Association for Thoracic Surgery http://dx.doi.org/10.1016/j.jtcvs.2013.08.040
}

However, it is unclear if the RA or the RITA is the better second arterial conduit ${ }^{10-12}$ during CABG-LITA. Several investigators ${ }^{13,14}$ have reported the RA to be the better option, some investigators ${ }^{15}$ have found no difference, whereas others ${ }^{16}$ have reported the RITA to be superior. All of these comparative studies had small numbers of patients, short- to midterm follow-up periods, and a high proportion of bypassing the right coronary artery with the second arterial graft. We sought to better define the second best arterial graft by comparing outcomes in propensitymatched patients receiving either a RA or free RITA to the circumflex coronary artery during CABG with LITA to the left anterior descending artery.

\section{METHODS \\ Patients}

We performed a retrospective cohort study of our 2 affiliated institutions' experiences using either the RA or the RITA to bypass the circumflex coronary artery during primary isolated CABG using the LITA to bypass the left anterior descending artery from January 1995 to January 2009. Beth Israel Medical Center (BIMC) and St. Luke's Roosevelt Hospital Center (SLR) are closely affiliated as part of Continuum Health Partners in New York, NY. Both centers maintain an identical New York State-mandated, prospectively collected database. BIMC used the RA as the primary second arterial conduit and SLR used the free RITA. Patients received additional 


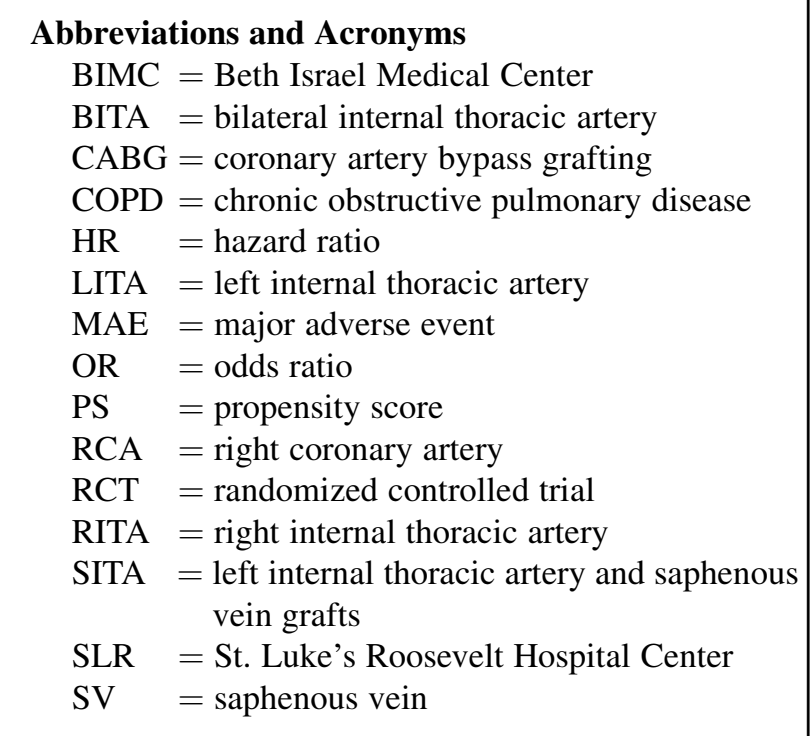

SV grafts as needed. All data were sent to the New York State Department of Health and also are maintained in a separate institutional database using Microsoft Access (Redmond, Wash). This study was approved by the medical centers' respective Institutional Review Boards, which waived written informed consent.

RA use at BIMC was at first selective, with approximately $33 \%$ of $\mathrm{CABG}$ patients receiving a $\mathrm{RA}$ for indications of age younger than 65 years or unavailable venous conduit. Contraindications to RA use were hemodialysis or chronic renal insufficiency, Raynaud's disease, and, more recently, radial artery catheterization. Overtime, use gradually increased. Currently, $75 \%$ of all patients receive a RA at BIMC using a liberalized age limit of younger than 80 years. Average total RA use was $43 \%$ over the past 17 years whereas RITA use at SLR has been consistently very high at near $60 \%$. There are no age restrictions at SLR and there were no contraindications to using a RITA graft. These different institutional grafting strategies resulted in a much younger RA population at BIMC than the SLR RITA group, as seen in Table 1.

A total of 6566 patients had isolated primary CABG using the LITA at BIMC $(n=4385)$ and at SLR $(n=2181)$ during the study period. Forty-one percent of these patients (2707) received a second arterial graft while the other 3859 patients received a LITA and SV grafts (SITA). RA and RITA were used mainly to bypass the circumflex vessels although the right coronary artery (RCA) occasionally was bypassed with these conduits. A total of 108 patients (98 at BIMC and 10 at SLR) receiving the second arterial graft to the RCA were excluded. The primary conduit to bypass the RCA was thus the SV. In addition, 111 patients (35 at BIMC and 76 at SLR) receiving both RA and RITA grafts were excluded. This resulted in 2488 patients at both institutions available for study: 1334 RA patients at BIMC and 1154 RITA patients at SLR.

\section{Surgical Techniques}

CABG was performed mostly on pump using cold blood cardioplegic arrest. Crystalloid cardioplegia was used early in the SLR experience. Off-pump surgery ( $1.1 \%$ of procedures at both BIMC and SLR) was performed when aortic disease precluded the safe use of cross-clamping or cardiopulmonary bypass. The RITA nearly always was used as a free graft. Both RA and RITA grafts were used as aortocoronary bypasses except if a lack of length or aortic disease precluded direct aortic anastomosis when the proximal anastomoses were performed on another RA, SV, or, rarely, LITA. BIMC performed the proximal anastomoses using a single cross-clamp technique whereas SLR used a partial occlusion clamp to perform the proximal anastomoses after removal of the cross-clamp. The RITA frequently was used as a sequential or Y graft $58 \%$ of the time for the RITA compared with only $18 \%$ of RA patients. In RA and RITA patients receiving more than 2 arterial grafts, an additional obtuse marginal, a large diagonal, or a ramus branch usually were grafted as the third arterial target vessel. SLR surgeons used the surgical microscope with $12 \times$ magnification for all anastomoses.

Our technique of radial artery harvest and preparation has been described previously. ${ }^{17}$ Since 2000 , we have harvested all conduits using an endoscopic approach. We previously found no advantage in open versus endoscopic harvesting. ${ }^{18}$ The internal thoracic arteries were harvested as pedicled grafts at both institutions. Occasional mechanical or papaverine dilation of the ITA was performed at both institutions.

\section{Study End Points}

The primary end points of the study were all-cause mortality and perioperative major adverse events (MAEs), which included surgical death, stroke, myocardial infarction, sternal wound infection, sepsis, reoperation for bleeding, respiratory failure, and renal failure. The Social Security Death Index (www.Genealogybank.com) was searched in October 2012 and was used to identify patients who died after hospital discharge. Surgical mortality included all patients who died during the index hospitalization or within 30 days after surgery if discharged.

MAEs were collected prospectively and were defined by the Department of Health Cardiac Surgery Reporting System (http://www.health.ny.gov/ statistics/diseases/cardiovascular/index.htmNYS). All MAEs occurred during the index hospitalization, except for sternal wound infection, which was reported up to 6 months postoperatively.

A secondary end point was graft patency. Symptom-driven cardiac catheterization was performed at our institutions on $17.7 \%$ of RA and $9.3 \%$ of RITA patients. We classified grafts as perfectly patent, diseased with more than $70 \%$ disease, or occluded. Grafts with string signs (diffuse narrowing of the graft to $<1 \mathrm{~mm}$ or Thrombolysis in Myocardial Infarction [TIMI] flow of 1) were considered occluded.

\section{Propensity Matching and Statistical Analysis}

All analyses were conducted using Stata statistical software version 12.1 (release 12; Stata Corporation, College Station, Tex). Univariate comparisons between RA and RITA graft patients were conducted using $t$ tests for normally distributed variates and 2-sample proportion tests for binary valued variates. Relationships with multivalued categoric variates were evaluated using $\chi^{2}$ tests.

Because of selection bias in assignment of patients to specific graft types, a bias-reduction technique was used to allow testing of the relative effect of RA grafts on survival and other postoperative outcomes. A logistic propensity scoring model (based on the following significant predictors of treatment probability: age, sex, ethnicity, year of surgery, ejection fraction, priority, myocardial infarction, hypertension, chronic obstructive pulmonary disease [COPD], heart failure, number of grafts, number of arterial grafts, hemodialysis, and triple-vessel disease) was developed to summarize covariate information regarding treatment selection (RA vs RITA) into a single scalar value (propensity score [PS]) and subsequently was used in a nearest-neighbor, caliper-constrained matching technique. ${ }^{19}$ A total of 1334 patients who had received a single RA graft were matched against a sample of 1154 patients who had received a single RITA graft. A total of 528 matched pairs $(\mathrm{N}=1056)$ of RA and RITA graft recipients were identified and used for subsequent analysis.

Unadjusted long-term survival of the 2 covariate-matched patient/graft subgroups was evaluated using Kaplan-Meier estimates and the log-rank statistic. A Cox proportional hazard regression was conducted to evaluate the hazard ratio of RA versus RITA adjusted for a set of covariates and comorbidities that were selected in a stepwise fashion using backward elimination. The proportional hazard assumption was tested and found to have been met. The following independent variables were entered into 
TABLE 1. Comparison of radial artery and right internal mammary artery patients

\begin{tabular}{|c|c|c|c|c|c|c|}
\hline & \multicolumn{3}{|c|}{ Before propensity matching } & \multicolumn{3}{|c|}{ After propensity matching } \\
\hline & Radial $(n=1334)$ & RITA $(n=1154)$ & $P$ value & Radial $(n=528)$ & RITA $(n=528)$ & $P$ value \\
\hline Years since $\mathrm{CABG} \pm \mathrm{SD}$ & $9.8 \pm 4.1$ & $8.8 \pm 4.5$ & $<.001$ & $10.0 \pm 4.2$ & $9.7 \pm 4.4$ & .292 \\
\hline All-cause mortality & $13.7 \%$ & $30.2 \%$ & $<.0001$ & $17 \%$ & $22.5 \%$ & .025 \\
\hline Mean age $(\mathrm{y} \pm \mathrm{SD})$ & $57.6 \pm 8.3$ & $65.7 \pm 10.8$ & $<.0001$ & $60.0 \pm 7.9$ & $61.0 \pm 11.0$ & .100 \\
\hline Male & $83 \%$ & $70.6 \%$ & $<.0001$ & $78.4 \%$ & $76.9 \%$ & .555 \\
\hline Female & $17 \%$ & $29.4 \%$ & $<.0001$ & $21.6 \%$ & $23.1 \%$ & .555 \\
\hline $\mathrm{BMI} \pm \mathrm{SD}$ & $29 \pm 5.9$ & $28.2 \pm 5.4$ & .237 & $28.8 \pm 6.9$ & $28.7 \pm 5.3$ & .615 \\
\hline Hispanic & $20.9 \%$ & $22.9 \%$ & $<.0001$ & 0.205 & 0.223 & .453 \\
\hline White & $67.7 \%$ & $66.8 \%$ & .641 & 0.688 & 0.706 & .503 \\
\hline Mean $\mathrm{EF} \pm \mathrm{SD}$ & $47.5 \pm 13.3$ & $45.8 \pm 14.7$ & .002 & $47.3 \pm 13.6$ & $47.5 \pm 14.4$ & .868 \\
\hline Transmural MI & $36.3 \%$ & $24.7 \%$ & $<.0001$ & $30.9 \%$ & $28.6 \%$ & .419 \\
\hline Stroke & $4.9 \%$ & $4.7 \%$ & .883 & $3.9 \%$ & $5.5 \%$ & .188 \\
\hline Cerebrovascular disease & $5.4 \%$ & $9.4 \%$ & $<.0001$ & $6.8 \%$ & $6.4 \%$ & .805 \\
\hline Aortoiliac PVD & $1.9 \%$ & $3.2 \%$ & .039 & $1.7 \%$ & $2.7 \%$ & .292 \\
\hline Femoral popliteal PVD & $5.2 \%$ & $9.6 \%$ & $<.0001$ & $7.8 \%$ & $8 \%$ & .909 \\
\hline Hemodialysis & $0.3 \%$ & $3.0 \%$ & $<.0001$ & $0.8 \%$ & $0.8 \%$ & 1.000 \\
\hline Creatinine value $>2.5 \mathrm{mg}$ & $1.8 \%$ & $3.0 \%$ & $<.001$ & $1.9 \%$ & $1.5 \%$ & .634 \\
\hline Calcified aorta & $3.8 \%$ & $7.7 \%$ & $<.0001$ & $5.1 \%$ & $6.4 \%$ & .356 \\
\hline Current CHF & $6.8 \%$ & $24.8 \%$ & $<.0001$ & $10.8 \%$ & $10 \%$ & .687 \\
\hline COPD & $18.5 \%$ & $7.7 \%$ & $<.0001$ & $10.4 \%$ & $10 \%$ & .839 \\
\hline Diabetes & $37.6 \%$ & $35.3 \%$ & .237 & $36.6 \%$ & $35.6 \%$ & .749 \\
\hline Hypertension & $66.6 \%$ & $48.4 \%$ & $<.0001$ & $56.8 \%$ & $56.3 \%$ & .852 \\
\hline Previous PCI & $18.4 \%$ & $13.4 \%$ & .001 & $16.9 \%$ & $15.5 \%$ & .559 \\
\hline \multicolumn{7}{|l|}{ Coronary vessel disease } \\
\hline Triple & $84.3 \%$ & $91.7 \%$ & $<.0001$ & $86.4 \%$ & $86.9 \%$ & .786 \\
\hline Double & $11.5 \%$ & $7.2 \%$ & $<.0001$ & $10.4 \%$ & $10.8 \%$ & .842 \\
\hline Single & $3.3 \%$ & $0.9 \%$ & $<.0001$ & $3 \%$ & $1.7 \%$ & .157 \\
\hline Left main & $28 \%$ & $30.3 \%$ & .209 & $31.1 \%$ & $29 \%$ & .460 \\
\hline Mean cross-clamp time \pm SD & $70.4 \pm 19.4$ & $70.0 \pm 26.6$ & .658 & $69.3 \pm 21.9$ & $67.0 \pm 25.8$ & .144 \\
\hline Mean Perfusion Time \pm SD & $93.3 \pm 23.4$ & $128.5 \pm 34.7$ & $<.0001$ & $92.6 \pm 25.2$ & $125.0 \pm 34.4$ & $<.0001$ \\
\hline Grafts per patient: \pm SD & $3.9 \pm 0.9$ & $4.0 \pm 0.9$ & $<.0001$ & $3.8 \pm 0.9$ & $3.8 \pm 0.9$ & .332 \\
\hline Arterial Grafts per patient \pm SD & $2.4 \pm 0.6$ & $3.1 \pm 0.7$ & $<.0001$ & $2.7 \pm 0.6$ & $2.8 \pm 0.7$ & .016 \\
\hline \multicolumn{7}{|l|}{ Major adverse events: } \\
\hline Operative mortality & $0.4 \%$ & $1.8 \%$ & $<.0001$ & $0.6 \%$ & $1.7 \%$ & .082 \\
\hline Permanent stroke & $0.9 \%$ & $2.4 \%$ & .003 & $0.8 \%$ & $2.1 \%$ & .069 \\
\hline Myocardial Infarction & $1.1 \%$ & $0.3 \%$ & .011 & $1.1 \%$ & $0.6 \%$ & .315 \\
\hline Sternal wound infection & $1.1 \%$ & $2.9 \%$ & .001 & $1.1 \%$ & $2.7 \%$ & .071 \\
\hline Septicemia & $0.8 \%$ & $0.7 \%$ & .707 & $0.8 \%$ & $0.6 \%$ & .705 \\
\hline Reoperation for bleeding & $1.4 \%$ & $2.5 \%$ & .049 & $1.5 \%$ & $1.9 \%$ & .634 \\
\hline Respiratory failure & $1.9 \%$ & $4.5 \%$ & $<.0001$ & $1.1 \%$ & $4.0 \%$ & .003 \\
\hline Renal failure & $0.4 \%$ & $1.6 \%$ & .005 & $0.6 \%$ & $0.6 \%$ & 1.000 \\
\hline
\end{tabular}

$B M I$, Body mass index; $C H F$, congestive heart failure; $E F$, ejection fraction; $M I$, myocardial infarction; $P C I$, percutaneous intervention; $P V D$, peripheral vascular disease; $R I T A$, right internal thoracic artery; $C A B G$, coronary artery bypass grafting; $C O P D$, chronic obstructive pulmonary disease; $S D$, standard deviation.

the Cox regression and the logistic regression models: conduit type, diabetes, hypertension, ejection fraction, COPD, age, femoral popliteal peripheral vascular disease, and congestive heart failure.

To further confirm that the choice of conduit had an independent effect on postoperative MAEs, we developed a logistic model for MAEs to estimate the effect of the conduit, adjusted for the PS, on all unmatched patients. We also developed a Cox proportional hazards regression model to estimate the hazard of death in RA patients referenced to RITA patients. The model was adjusted using the PS to reduce selection bias. We also performed a propensity analysis in the 3859 concurrent patients undergoing CABG using LITA and only SV grafts at both institutions. Of the 2918 BIMC patients and the 941 SLR patients, 571 matched pairs were analyzed. Finally, we compared our institutions' risk-adjusted mortality using the
New York State Department of Health Cardiac Surgery Reporting System data available on their website (http://www.health.ny.gov/statistics/ diseases/cardiovascular/index).

\section{RESULTS}

\section{Patient Data and Survival}

Table 1 shows the patient risk factors, intraoperative data, and MAEs for unmatched and matched RA and RITA patients. Briefly, the unmatched RA patients were much younger (average age, 57.6 y for RA compared with $65.7 \mathrm{y}$ for RITA patients) and mostly male 
(RA, $83.0 \%$ vs RITA, $70.6 \%$ ). Both groups had a similar number of diabetic patients. Coronary artery disease was more extensive in the RITA group, but the number of bypass grafts per patient was similar (RA, 3.9; RITA, 4.0) in both groups. The RA unmatched patients had $2.4 \pm 0.6$ arterial grafts per patient compared with $3.1 \pm 0.7$ arterial grafts per patient for the RITA patients, reflecting the prevalent use of sequential grafting using the RITA (and often the LITA) in the RITA group. In all, $31 \%$ of the RA patients and $79 \%$ of the RITA patients received more than 2 arterial grafts. Among RA patients, $18 \%$ had sequential or Y grafts, $6.6 \%$ had bilateral RA grafts, and a long RA occasionally could be used for 2 individual aortocoronary grafts. For RITA patients, $58 \%$ had sequential or Y grafts. Sequential LITA grafting was performed in $43 \%$ of the RITA patients and in $3.8 \%$ of the RA patients.

Long-term follow-up evaluation averaged $9.0 \pm 4.3$ years for the RA patients and $8.5 \pm 4.6$ years for the RITA patients, with a range 0.1 to 16 years. There were a total of 178 postdischarge deaths in the RA group and 327 postdischarge deaths in the RITA group. Including the surgical deaths, the total all-cause mortality was $13.7 \%$ in the RA patients and $30.2 \%$ in the RITA patients $(P<.0001)$. Long-term Kaplan-Meier survival strongly favored RA grafting in the unmatched patients as seen in Figure $1, A$ (log-rank test, $P<.0001)$. As outlined in Table 1, better outcomes and fewer major complications in the RA group likely reflected the significantly older age, more extensive disease, and more co-morbidities in the unmatched RITA patients.

RA use was a strong predictor of decreased MAEs (OR, 0.49; 95\% confidence interval [CI], 0.32-0.77; $P=.002)$ in all unmatched patients after adjustment using the propensity-adjusted logistic model. In addition, after adjustment using the PS-adjusted Cox regression model, RA use was found not to be a predictor of mortality (hazard ratio $[\mathrm{HR}], 0.87 ; 95 \% \mathrm{CI}, 0.67-1.14 ; P=.322$ ).

\section{Propensity-Matched Patient Outcomes}

Table 1 shows the matched RA and RITA data in 1056 patients. The 2 groups were well matched by age, sex, vascular disease, diabetes, left ventricular function, extent of disease, and completeness of revascularization. Crossclamp times were the same before and after matching. Perfusion times were longer in the RITA group, reflecting the additional time for use of the surgical microscope and more sequential grafting.

Table 1 also shows the MAEs for the matched patients. There was a trend toward more strokes and sternal wound infections in the RITA patients and significantly more respiratory failure $(P=.003)$. All MAEs were fewer in the RA group $(7.6 \%$ vs $14.0 \% ; P=.001)$. After adjusting for multiple comparisons, rates of respiratory failure (Sidak-adjusted $P=.031$ ) and overall MAEs

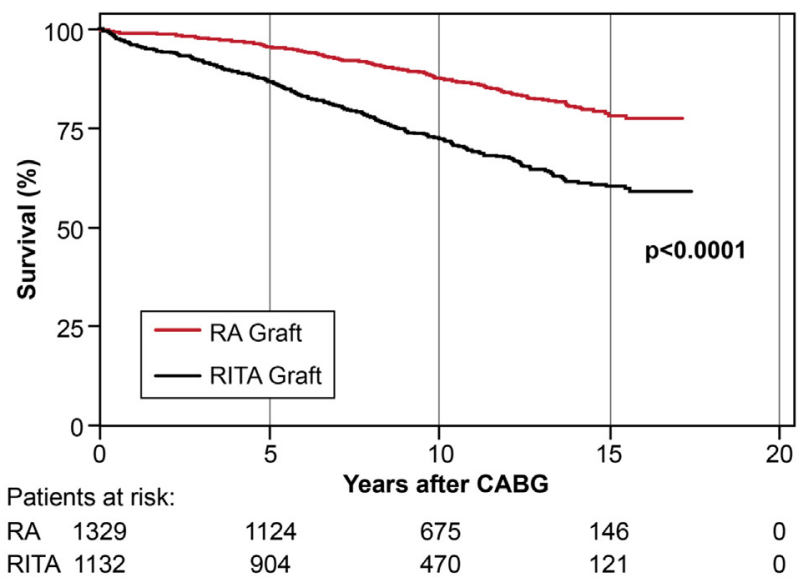

A

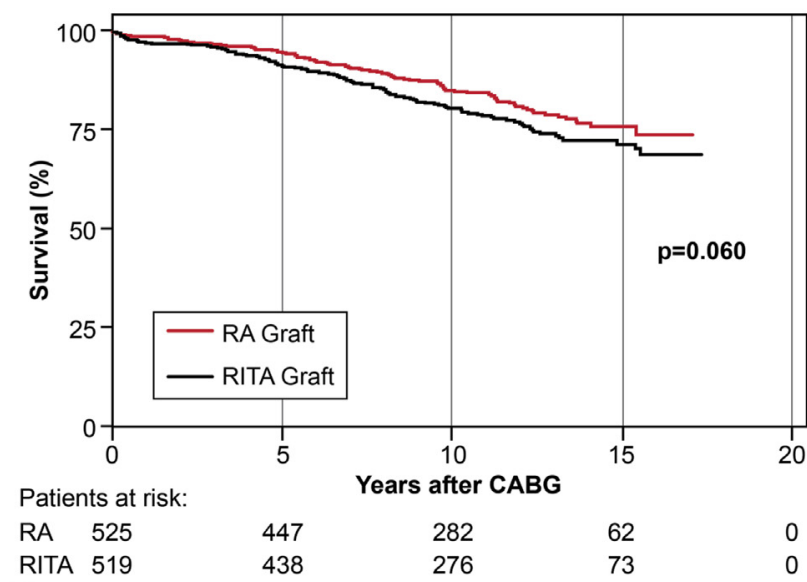

B

FIGURE 1. A, Comparison of the unadjusted Kaplan-Meier estimated survival for all RA and RITA patients $(P<.0001$, log-rank test). $\mathrm{B}$, Comparison of the Kaplan-Meier survival for propensity-matched RA and RITA patients $(P=.060, \log$-rank test). $C A B G$, Coronary artery bypass grafting; $R A$, radial artery; RITA, right internal thoracic artery.

(Sidak-adjusted $P=.023$ ) remained significantly better using the RA. Finally, logistic regression modeling showed that use of a RA conduit was a significant predictor of reduced MAEs (odds ratio [OR], 0.48; 95\% CI, $0.30-0.77 ; P=.002$ ).

Hospital and 30-day mortality was $0.6 \%$ for the RA and $1.7 \%$ for the RITA patients, which was not statistically different $(P=.082)$. There were an additional 87 late deaths $(16.6 \%)$ in the RA group and 110 late deaths $(21.2 \%)$ in the RITA group. After excluding early hospital deaths, propensity-matched RA and RITA patients had similar long-term Kaplan-Meier survival as seen in Figure 1, $B$. Ten-year survival was $85 \%$ for RA and $80 \%$ for RITA patients, which was not statistically significant (log-rank test, $P=.060$ ). The corresponding 0 - to 15 -year mortality rate was $20.8 \%$ higher for the RITA group. Combined early and late all-cause mortality was $17 \%$ for RA and $22.5 \%$ for RITA patients $(P=.025)$. 
Table 2 shows the results of Cox regression modeling. Although use of a RA graft decreased mortality by $15 \%$, RA use was not an independent predictor of decreased mortality (HR, 0.85; 95\% CI, 0.64-1.13; $P=.257$ ). COPD, diabetes, peripheral vascular disease, congestive heart failure, hypertension, a calcified ascending aorta, age, and left ventricular function were all independent predictors of increased mortality in the matched patients.

Table 3 shows that the use of a RA was a strong predictor of decreased MAEs in diabetic patients (OR, 0.32; 95\% CI, $0.15-0.68 ; P=.003$ ), obese patients (OR, $0.15 ; 95 \%$ CI, 0.06-0.39; $P<.001$ ), COPD patients (OR, 0.05; 95\% CI, 0.01-0.57; $P=.016$ ), and those patients older than 60 years (OR, 0.40; 95\% CI, 0.20-0.79; $P=.009)$. However, Table 3 shows that use of a RA significantly improved survival only in patients with COPD (HR, 0.49; 95\% CI, $0.24-0.98 ; P=.045)$ and with age older than 60 years (HR, 0.71; 95\% CI, 0.51-0.99; $P=.050$ ). Overall survival in these other subgroups of patients was not statistically different between the RA and RITA patients.

\section{LITA/SV Patient Outcomes}

To address the possibility that surgeon or institutional practice differences and not the choice of conduit caused the different RA versus RITA outcomes, we first compared our New York State Department of Health risk-adjusted mortality rates for all isolated CABG over the 14-year period of the study. There was no difference in mortality rate (BIMC, $2.22 \%$; SLR, $2.35 \% ; P=.562$ ). Second, in the concurrent group of matched SITA patients, the Kaplan-Meier 1-, 5-, and 10-year survival rates were $95 \%, 83 \%$, and $66 \%$, respectively, for BIMC, and were $92 \%, 79 \%$, and $66 \%$, respectively, for SLR patients $(P=.07$, log-rank test $)$, and MAE rates were similar (RA, $21 \%$ vs RITA, $24 \% ; P=.22$ ). In addition, Cox regression modeling showed no difference in mortality (HR, 1.00; 95\% CI, 0.84-1.20; $P=.938$ ), and logistic regression showed no difference in the rate of MAEs (OR, 0.76; 95\% CI, 0.53-1.08; $P=.134$ ). The SLR $4.6 \%$ stroke rate (compared with $1.2 \%$ at BIMC) was

TABLE 2. Independent predictors of mortality in 1056 matched RA and RITA patients after CABG/LITA

\begin{tabular}{lccc}
\hline & HR & $\mathbf{9 5} \%$ CI & $\boldsymbol{P}$ value \\
\hline Radial artery use & 0.85 & $0.64-1.13$ & .277 \\
Femoral PVD & 2.31 & $1.57-3.42$ & $<.0001$ \\
Age per year & 1.06 & $1.04-1.08$ & $<.0001$ \\
Diabetes & 1.55 & $1.17-2.07$ & .003 \\
Hypertension & 1.63 & $1.17-2.27$ & .004 \\
COPD & 1.66 & $1.16-2.36$ & .005 \\
Ejection fraction & 0.99 & $0.98-1.00$ & .010 \\
CHF & 1.59 & $1.10-2.31$ & .015 \\
\hline
\end{tabular}

$C H F$, Congestive heart failure; $P V D$, peripheral vascular disease; $C O P D$, chronic obstructive pulmonary disease; $H R$, hazard ratio; $C I$, confidence interval.
TABLE 3. Adjusted HRs for death and adjusted ORs for MAEs in propensity-matched patient subgroups

\begin{tabular}{lccccc}
\hline \multicolumn{5}{c}{ Patients, } & \multicolumn{3}{c}{$\boldsymbol{P}$} & $\begin{array}{c}\boldsymbol{P} \\
\text { Risk factor }\end{array}$ & $\mathbf{n}$ & HR $(\mathbf{9 5} \% \mathbf{C I})$ & $\begin{array}{c}\text { value } \\
\text { OR }(\mathbf{9 5} \% \mathbf{C I})\end{array}$ & value \\
\hline Diabetes & 381 & & & & \\
RA & 193 & $0.86(0.57-1.29)$ & .474 & $0.32(0.15-0.68)$ & .003 \\
RITA & 188 & Reference & & Reference & \\
Obesity & 373 & & & & \\
RA & 181 & $0.88(0.56-1.38)$ & .578 & $0.15(0.06-0.39)$ & $<.001$ \\
RITA & 192 & Reference & & Reference & \\
COPD & 108 & & & & \\
RA & 55 & $0.49(0.24-0.98)$ & .045 & $0.05(0.01-0.57)$ & .016 \\
RITA & 53 & Reference & & Reference & \\
Female & 236 & & & & \\
RA & 114 & $0.97(0.55-1.70)$ & .914 & $0.40(0.16-1.00)$ & .051 \\
RITA & 122 & Reference & & Reference & \\
EF $<40 \%$ & 335 & & & & \\
RA & 150 & $0.74(0.48-1.12)$ & .153 & $0.47(0.20-1.11)$ & .087 \\
RITA & 185 & Reference & & Reference & \\
Age $>60$ y & 519 & & & & \\
RA & 241 & $0.71(0.51-0.99)$ & .050 & $0.40(0.20-0.79)$ & .009 \\
RITA & 278 & Reference & & & \\
\hline
\end{tabular}

Adjusted for age, sex, previous myocardial infarction, femoral popliteal disease, aorto-iliac disease, cerebrovascular disease, stroke, diabetes, COPD, creatinine level $>2.5 \mathrm{mg} / \mathrm{dL}$, hemodialysis, and triple-vessel disease. $E F$, Ejection fraction; $H R$, hazard ratio; $O R$, odds ratio; $R A$, radial artery; $R I T A$, right internal thoracic artery; $C O P D$, chronic obstructive pulmonary disease; $C I$, confidence interval.

the only MAE that was significantly different (Sidakadjusted $P=.011$ ); there were no differences in the respiratory failure rate at BIMC $(5.4 \%)$ versus SLR $(8.4 \%)$ (Sidak-adjusted $P=.555)$ and the sternal infection rates $(1.1 \%$ at BIMC vs $0.9 \%$ at SLR). These similar overall outcomes in all CABG patients and in the concurrent SITA patients suggest similar institutional practices and further suggest that the differences in RA versus RITA MAEs are the result of the choice of conduit and not the institution.

\section{Graft Patency}

Of the total cohort of 2488 patients, 343 patients (13.8\%) had symptom-driven cardiac catheterization at our institutions 0.1 to 15.5 years after CABG. The mean time to catheterization was $5.2 \pm 3.7$ years at BIMC and $5.0 \pm 3.9$ years at SLR. The total percentage of patients undergoing catheterization at BIMC was $17.7 \%$ (236 of 1334 patients) and at SLR was $9.3 \%$ (107 of 1154 patients).

Overall, a total of 1372 anastomoses in 236 RA and 107 RITA patients were evaluated. Overall patency for the RA was $83.9 \%$ (276 of 329 anastomoses) and, for the RITA, patency was $87.4 \%$ (160 of 183 anastomoses), which was not statistically different $(P=.155)$. Overall (343 patients) LITA patency was $92.7 \%$ in 396 anastomoses and SV patency was $56.7 \%$ in 464 anastomoses. LITA $(P<.0001)$, RITA $(P<.0001)$, and RA $(P<.0001)$ patency were each significantly better than SV patency. 
The patency of combined RA sequential (10 anastomoses in 5 patients) and $\mathrm{Y}$ grafts ( 36 anastomoses in 18 patients) was $78 \%$ (36 of 46 ) versus a single RA to circumflex aortocoronary graft patency of $84.8 \%$ (240 of 283) $(P=.339)$. RITA sequential (132 distal anastomoses in 61 patients) and Y graft (12 distal anastomoses in 6 patients) combined patency was $86.8 \%$ (125 of 144 ) versus $87.5 \%$ (35 of 40) patency for single RITA grafts to the circumflex coronary artery $(P=.908)$.

\section{DISCUSSION}

Our 18-year study of 528 matched pairs of CABG-LITA patients comparing RA and RITA grafts to bypass the left circumflex coronary artery is the largest reported series attempting to better define the second best arterial graft. We compared long-term survival in our 2 affiliated centers each committed to arterial grafting, one using the RA and the other using the free RITA. We found that long-term survival was similar in CABG-LITA patients receiving either the RA or free RITA to bypass the circumflex coronary artery. Major adverse events were fewer with the RA and use of the RA was protective from MAEs, especially in diabetic, obese, COPD, and older patients. In addition, COPD and older patients had better survival with RA grafting. Midterm RA patency was similar to RITA patency.

There are few previous studies comparing the RA versus the RITA in patients undergoing CABG with the LITA. All studies lacked long-term follow-up evaluation and all included a high proportion in whom the second arterial graft bypassed the right coronary artery. Most studies supported the RA or found no survival differences. Caputo et $\mathrm{al}^{13}$ found similar survival at 18 months in $325 \mathrm{RA}(62 \%$ to the circumflex coronary artery) and 336 RITA ( $6 \%$ as free grafts and $47 \%$ to the circumflex) unmatched patients. They concluded that the use of the RA (preferentially used in diabetic, older, and COPD patients) had a strong protective effect against all causes of death. Hayward et $\mathrm{al}^{14}$ reported similar 5-year survival and patency in a prospective randomized controlled trial (RCT) — the Radial Artery Patency and Clinical Outcomes trial-in patients younger than 70 years, comparing the RA (198 patients) with the free RITA (196 patients) to bypass the next best coronary artery (which was the circumflex coronary artery in $54 \%$ of the RA group and $61 \%$ in the RITA group). They found significantly improved adjusted event-free survival at 18 months with use of the RA. RA patency was $94 \%$ and RITA patency was $87 \%$. In the only other RCT comparing RA with RITA grafting, Nasso et $\mathrm{al}^{15}$ found no difference in survival at 3 years between 202 RA ( $77 \%$ to the circumflex) and 198 free RITA ( $74 \%$ to the circumflex) patients. Our overall findings are consistent with these 3 smaller, midterm studies supporting use of the RA versus the RITA (mostly as free grafts).
One study supported the RITA and reported quite poor outcomes using the RA. Ruttmann et $\mathrm{al}^{16}$ reported much better event-free survival at 33 months in 277 RITA ( $42 \%$ as free grafts) patients propensity matched to 277 RA patients. Patency of the RA $(62 \%)$ was inferior to ITA $(90 \%)$ and even SV (79\%) patency. The striking finding of this study was the disproportionally high rate of postoperative complications in the RA patients. The rates of postoperative myocardial infarction $(3.6 \%)$ and stroke $(3.6 \%)$ were each 9-fold higher in the RA patients than in the RITA patients. The rates of reoperation for bleeding $(6.5 \%)$ and sternal dehiscence $(3.6 \%)$ in RA patients were also much higher than usually reported. They also reported that $8 \mathrm{RA}$ patients needed emergent redo CABG for acutely failed RA grafts, an event we have not observed in more than 1850 RA patients. ${ }^{17}$ These unusual findings may reflect major differences in the harvesting, deployment, and surgical techniques of RA grafting. These limitations clearly undermine the validity of the conclusion by Ruttmann et $\mathrm{al}^{16}$ that the use of the RITA but not the RA improves long-term survival after CABG. Thus, our findings and a critical review of the available RA versus RITA literature suggest a similar survival rate using either the RA or RITA with a trend toward better event-free survival using the RA.

We found a very strong protective effect of RA grafting on MAEs. The lower rates of sternal wound infection and respiratory failure in the RA patients suggest the cautious use of bilateral internal thoracic artery (BITA) harvesting in obese, diabetic, older, and COPD patients at risk for these complications. Although there may be somewhat differing protocols for ventilator management at our 2 institutions, there is a general consensus to extubate patients as early as possible and to re-intubate a patient when clearly indicated. Although the differing rates of respiratory failure may be related to institutional practices, we believe that the likely factor causing the difference is the choice of conduit in selected patients. In diabetic patients, we found a highly significant protective effect of RA grafting on MAEs (Table 3). Compared with SV grafting, Hoffman et $\mathrm{al}^{20}$ have shown survival benefits and Singh et $\mathrm{al}^{21}$ have shown patency benefits of RA grafting in diabetic patients. In addition, Dorman et $\mathrm{al}^{22}$ and Puskas et $\mathrm{al}^{3}$ recently reported a clear survival benefit of BITA grafting compared with SITA grafting in diabetic patients without a statistically significant difference in sternal wound infections, although Puskas et $\mathrm{al}^{3}$ reported an adjusted $85 \%$ increase in sternal infections in the BITA group. Taggart et $\mathrm{al}^{23}$ found a clear increase $(1.9 \%$ vs $0.6 \% ; R R, 3.24)$ in sternal wound infections in the only RCT comparing BITA with SITA grafting. The evidence thus strongly supports additional arterial grafting in diabetic patients and, although not universal, there appears to be a significantly increased risk of sternal wound infections in diabetic patients receiving 
BITA grafts. The recent Center for Medicare and Medicaid decision not to pay for a sternal wound infection, defined as a "never event," adds to the appropriate reluctance to use BITA grafting in diabetic (as well as in obese and COPD) patients. RA grafting is an excellent alternative to RITA grafting in diabetic and other patients at high risk for MAEs. Nonetheless, RITA grafting is still superior to SV grafting in all patients and both RA and RITA grafting have clearly documented long-term survival benefits compared with SV grafting.

The RITA is believed to be the better conduit by many surgeons based on anecdotal experience and a sense of less predictable RA patency ${ }^{12}$ despite multiple studies showing excellent (from $82 \%$ to $98 \%$ ) 1- to 7 -year RA patency. ${ }^{17,24-28}$ The most frequently cited evidence for poor RA patency is the study by Khot et al. ${ }^{29}$ They found a 51\% RA patency at 18 months in 310 of 27,211 patients undergoing cardiac catheterization from 1996 to 2001. However, $22 \%$ of these 310 patients had reoperative CABG and only $63 \%$ received postoperative antispasm medication. In addition, $25 \%$ of these patients had a RITA graft, suggesting that the RA was used for third- or fourth-order target vessels. This study had clear limitations in comparing contemporary RA patency in primary CABG procedures performed in patients with the RA used for second-order target vessels. Thus, the majority of the literature and our results support excellent midterm patency of RA conduits.

We found equivalent 5-year RA and RITA patency as did the Radial Artery Patency and Clinical Outcomes investigators. ${ }^{30}$ They subsequently reported a $90 \%$ RA patency and an $83 \%$ RITA patency that was similar to our $83.9 \%$ RA patency and $87.5 \%$ RITA patency. In addition, Tatoulis et $\mathrm{al}^{28}$ found a RA patency of $89 \%$ at 4 years in their study of 1108 RA angiograms. They also noted a $92.5 \%$ patency in RA grafts in place more than 5 years, leading the investigators to conclude that late patency of RA grafts is similar to reported RITA patency. However, in a later report, Tatoulis et $\mathrm{al}^{31}$ found 10- and 15-year RITA patency of $90 \%$ and $79 \%$, respectively, in their large study of 991 RITA angiograms. They also found that 10 -year RA patency was now only $78 \%$, leading the investigators to alter their previous conclusion. They now suggest that RITA patency probably is better than RA patency, although long-term RA patency data were limited. The majority of the literature thus suggests a RA midterm patency very similar to RITA patency but, clearly, more long-term studies are needed to better define the late patency of RA grafts.

Our study had several important limitations. It was a retrospective study subject to patient selection bias. In addition, different institutional arterial grafting preferences and practices resulted in significant heterogeneity between the RA and RITA patient groups. Propensity matching was thorough and designed to minimize patient selection bias, but there remains a possibility of uncontrolled confounding effects and that the difference in outcomes was the result of the different institutions' practice and not the choice of conduit. We further addressed this bias by using the propensity score in logistic and regression multivariable analyses in all unmatched RA and RITA patients, which confirmed our propensity-matched findings. In addition, we compared our overall 14-year New York State risk-adjusted mortality rates for our 2 institutions and performed a propensity analysis of concurrent SITA patients and neither found any differences in outcomes, suggesting similar institutional and surgeon practices and systems of care. Available hospital data points were limited to those reported to the New York State database. All-cause mortality was used to determine survival; the cause of death and other cardiac events were not available. Cardiac catheterization data were limited to only our institutions and the mechanism of graft failure was not determined. Our RITA grafts were all free, pedicled grafts, which possibly lack the potential long-term survival benefits of in situ grafts (although Tatoulis et $\mathrm{al}^{31}$ showed identical 10-year patency of free and in situ RITA grafts, which strongly suggests equivalent free and in situ RITA long-term survival), and the possible lower sternal infection rates of skeletonized BITA grafts. ${ }^{32}$ Finally, there were clear differences in the practices of our 2 institutions that may have contributed to the differences in short-term outcomes. In particular, the greater commitment to more complete arterial grafting using sequential grafting and the use of the surgical microscope resulted in longer bypass times, which may have contributed to the higher MAE rates in the RITA patients. The findings of Fuqui et $\mathrm{al}^{33}$ and our finding of equivalent patency in sequential and single free RITA grafts strongly suggests that long-term survival is not impacted negatively by using sequential grafts.

We conclude that either the RA or free RITA may be used to achieve the well-documented survival benefit of multiple arterial grafting, but COPD or older patients probably should have a RA graft. The second best arterial graft to bypass the circumflex coronary artery during $\mathrm{CABG}$ with LITA may be the RA given the high rates of diabetes, obesity, and lung disease in the increasingly elderly patients undergoing CABG. Finally, multiple arterial grafting is an important strategy during $\mathrm{CABG}$ and the choice of the second arterial conduit should be guided by patient profiles and surgeon preferences.

\section{References}

\footnotetext{
1. Lytle BW, Blackstone EH, Sabik JF, Houghtaling P, Loop FD, Cosgrove DM The effect of bilateral internal thoracic artery grafting on survival during 20 postoperative years. Ann Thorac Surg. 2004;78:2005-14.

2. Kurlansky PA, Traad EA, Dorman MJ, Galbut DL, Zucker M, Ebra G. Thirtyyear follow-up defines survival benefit for second internal mammary artery in propensity-matched groups. Ann Thorac Surg. 2010;90:101-8.

3. Puskas JD, Sadiq A, Vassiliades TA, Kilgo PD, Lattouf LM. Bilateral internal thoracic artery grafting is associated with significantly improved long-term survival, even among diabetic patients. Ann Thorac Surg. 2012;94:710-6.
} 
4. Locker C, Schaff HV, Dearani JA, Joyce LD, Park SJ, Burkhart HM, et al. Multiple arterial grafts improve late survival of patients undergoing coronary artery bypass surgery: analysis of 8622 patients with multivessel disease. Circulation. 2012;126:1023-30.

5. Cohen G, Tamariz MG, Sever JY, Liaghati N, Guru V, Christakis GT, et al. The radial artery versus the saphenous vein graft in contemporary CABG: a case-matched study. Ann Thorac Surg. 2001;71:180-6.

6. Zacharias A, Habib RH, Schwann TA, Riordan CJ, Durham SJ, Shah A. Improved survival with radial artery versus vein conduits in coronary bypass surgery with left internal thoracic artery to left anterior descending artery grafting. Circulation. 2004;109:1489-96.

7. Tranbaugh RF, Dimitrova KR, Friedmann P, Geller CM, Harris LJ, Stelzer P, et al. Radial artery conduits improve long-term survival after coronary artery bypass grafting. Ann Thorac Surg. 2010;90:1165-72.

8. Schwann TA, Engoren M, Bonnell M, Clancy C, Habib RH. Comparison of late coronary artery bypass graft survival effects of radial artery versus saphenous vein grafting in male and female patients. Ann Thorac Surg. 2012;94:1485-91.

9. Sabik JF. Understanding saphenous vein graft patency. Circulation. 2011;124: 273-5

10. Gardner G. Searching for the second-best coronary artery bypass graft: is it the radial artery? Circulation. 2007:115:678-80.

11. Slaughter MS. Conduits for Surgical. Arterial revascularization-the answer is.... Circulation. 2011;124:1313-4.

12. Lytle BW. Radial versus right internal thoracic artery as a second arterial conduit for coronary surgery: early and midterm outcomes. J Thorac Cardiovasc Surg. 2003; 126:5-6

13. Caputo M, Reeves B, Marchetto G, Mahesh B, Kim K, Angelini G. Radial versus right internal thoracic artery as a second arterial conduit for coronary surgery: early and midterm outcomes. J Thorac Cardiovasc Surg. 2003;126:39-47.

14. Hayward PAR, Hare DL, Gordon I, Matalanis G, Buxton BF. Which arterial conduit? Radial artery versus free right internal thoracic artery: six-year clinical results of a randomized controlled trial. Ann Thorac Surg. 2007;84:493-7

15. Nasso G, Coppola R, Bonifazi R, Piancone F, Bossetti G, Speziale G. Arterial revascularization in primary coronary artery bypass grafting: direct comparison of 4 strategies. Results of the stand-in-Y mammary study. J Thorac Cardiovasc Surg. 2009;137:1093-100.

16. Ruttmann E, Fischler N, Sakic A, Chevtchik O, Alber H, Schistek R, et al. Second internal thoracic artery versus radial artery in coronary artery bypass grafting: a long-term, propensity score-matched follow-up study. Circulation. 2011;124: 1321-9.

17. Tranbaugh RF, Dimitrova KR, Friedmann P, Geller CM, Harris LJ, Stelzer P, et al. Coronary artery bypass grafting using the radial artery: clinical outcomes, patency and need for reintervention. Circulation. 2012;126(suppl 1):S170-5.

18. Dimitrova KM, Hoffman DM, Geller CM, Dienstag B, Cohen BC, Tranbaugh RF. Patency of endoscopically harvested radial artery grafts. Innovations. 2010;5:265-9.

19. Leuven E, Sianesi B. PSMATCH2: Stata module to perform full Mahalanobis and propensity score matching, common support graphing, and covariate imbalance testing. Available at: http://ideas.repec.org/c/boc/bocode/s432001.html. Version 4.0.6. 2003. Accessed March 2013.

20. Hoffman DM, Dimitrova KR, DeCastro H, Friedmann P, Geller CM, Ko W, et al. Improving long term outcomes for diabetic patients undergoing surgical revascularization by use of the radial artery conduit: a propensity matched study. J Cardiothorac Surg. 2013;8:27-34.

21. Singh SK, Desai ND, Petroff SD, Deb S, Cohen EA, Radhakrishnan S, et al. The impact of diabetic status on coronary artery bypass graft patency: insights from the radial artery patency study. Circulation. 2008;118(suppl 1):S222-5.

22. Dorman MJ, Kurlansky PA, Traad EA, Galbut DL, Zucker M, Ebra G. Bilateral internal mammary grafting enhances survival in diabetic patients: a 30-year follow-up of propensity score-matched cohorts. Circulation. 2012;126:2935-42.

23. Taggart DP, Altman DG, Gray AM, Lees B, Nugara F, Yu LM, et al. Randomized trial to compare bilateral versus single internal mammary coronary artery bypass grafting: 1 year results of the Arterial Revascularization Trial (ART). Eur Heart J. 2010;31:2470-81.

24. Desai ND, Cohen EA, Naylor CD, Fremes SE. A randomized comparison of radial-artery and saphenous-vein coronary bypass grafts. $N$ Engl J Med. 2004; 351:2302-9.

25. Collins P, Webb CM, Chong CF, Moat NE. Radial artery versus saphenous vein patency randomized trial: five-year angiographic follow-up. Circulation. 2008; 117:2859-64.
26. Desai ND, Naylor D, Kiss A, Cohen EA, Feder-Elituv R, Miwa S, et al. Impact of patient and target-vessel characteristics on arterial and venous bypass graft patency: insight from a randomized trial. Circulation. 2007;115: 684-91

27. Buxton BF, Raman JS, Ruejgsakulrach P, Gordon I, Rosalion A, Bellomo R, et al. Radial artery patency and clinical outcomes: five year interim results of a randomized trial. J Thorac Cardiovasc Surg. 2003;125:1363-71.

28. Tatoulis J, Buxton BF, Fuller JA, Meswani M, Theodore S, Power N, et al. Long term patency of 1108 radial-coronary angiograms over 10 years. Ann Thorac Surg. 2009;88:23-30.

29. Khot UN, Friedman DT, Pettersson G, Smedira NG, Li J, Ellis SG. Radial artery bypass grafts have an increased occurrence of angiographically severe stenosis and occlusion compared with left internal mammary arteries and saphenous vein grafts. Circulation. 2004;109:2086-91

30. Hayward PA, Gordon IR, Hare DL, Matalanis G, Horrigan ML, Rosalion A, et al. Comparable patencies of the radial artery and right internal thoracic artery or saphenous vein beyond 5 years: results from the Radial Artery Patency and Clinical Outcomes trial. J Thorac Cardiovasc Surg. 2010;139:60-7.

31. Tatoulis J, Buxton BF, Fuller JA. The right internal thoracic artery: the forgotten conduit-5766 patients and 991 angiograms. Ann Thorac Surg. 2011;92:9-17.

32. DePaulis R, deNotaris S, Nardella S, Zeitani J, Del Giudice C, DePeppo A, et al. The effect of bilateral internal thoracic artery harvesting on superficial and deep sternal infection: the role of skeletonization. J Thorac Cardiovasc Surg. 2005; 129:536-43

33. Fuqui T, Tabata M, Morita S, Takanashi S. Sequential free right internal thoracic artery grafting for multivessel coronary artery bypass grafting. J Thorac Cardiovasc Surg. 2012;144:824-9.

\section{Discussion}

Dr James Tatoulis (Parkville, Victoria, Australia). I have no disclosures but I am an advocate for arterial grafts.

Dr Tranbaugh, congratulations on the delivery, content, and clarity of your presentation. It is 40 years since Carpentier first introduced the radial artery, 20 years since its resurrection by Acar, and bilateral ITAs have been used for over 30 years, yet fewer than $10 \%$ of coronary bypass operations worldwide have 2 or more arterial grafts. Dr Tranbaugh and his colleagues are to be commended on an excellent further contribution to the knowledge on arterial grafts.

Having previously shown superior long-term survival for LITA plus radial artery over LITA plus saphenous vein graft, they have now focused on the pragmatic question: which is the best second arterial graft, the radial or the RITA? The radial is long, robust, there are 2, it is easy and quick to harvest, and not burdened by sternal and pulmonary problems. The RITA, however, is biologically identical to the left ITA, universally acknowledged to be the best graft.

Their excellent, large, propensity-matched patency and outcome study spanning 18 years show similar excellent survival at 10 years, $85 \%$ and $80 \%$, and similar patency, $84 \%$ and $87 \%$, for the radial and RITA, respectively. However, there were more major adverse events in the RITA group: stroke, sternal infection, and respiratory failure. None significant individually but together they were. Hence, the clinical results favored the radial over the RITA, especially in obese patients and those with diabetes and chronic obstructive pulmonary disease.

I have a few questions. There were no contraindications to using the RITA, and in this group, a side-biting clamp was used, but not in the radial group. Can you please comment on the possible contribution of side-biting clamps to the higher stroke rate and whether the surgical strategy and technique 
actually created a difference in the result, not the choice of graft?

Dr Tranbaugh. Thank you very much, Dr Tatoulis, for your kind comments and your excellent point. The difference in stroke rates between the radial artery and RITA patients was likely due to using the single-clamp technique versus the side-biting clamp for the proximal anastomoses. Our practice is to use the single-clamp technique, which likely decreases the risk of stroke. We did not specifically look at that in this study, but that certainly was one of the suggestions of our study.

Dr Tatoulis. Thank you. Obesity, diabetes, and chronic obstructive airway disease are known risk factors for sternal infection and pulmonary problems in bilateral ITAs, and these could be possibly ameliorated by a skeletonized harvest. Will these findings encourage your group to avoid BITA in such patients or use skeletonized rather than pedicled ITAs?

Dr Tranbaugh. We do not have experience with skeletonized ITAs and we have used the pedicled approach. I certainly think that the enthusiasm for bilateral ITAs in obese diabetics with this data has changed the outlook at St. Luke's, and I think appropriately so.

Dr Tatoulis. Finally, spasm and competitive flow are significant problems for arterial grafts, and the radial is especially vulnerable. Can you briefly describe your strategy to overcome these issues both in the study and in your group's daily practice?

And, as an addendum, can I possibly entice you to be a bit more definitive in your conclusion? Do you think there is no difference between those 2 grafts at 10 years or do you favor the radial?

Thank you for your excellent contribution.

Dr Tranbaugh. Thanks very much. Radial artery spasm is real, as you well know, and I think it is very important to use a no-touch technique. We harvest the radial using an endoscopic technique, which we feel is a bit safer; for the last 13 years it has been our preferred technique. We are very cautious in the operating room, using heparinized blood with diltiazem and papaverine to gently irrigate the radial. We keep patients on intraoperative diltiazem and then postoperatively switch to intravenous nitroglycerin and maintain the patients for 6 months on long-term oral nitrates.

We have, fortunately, seen very little acute spasm of the radial artery. We have only had one intraoperative case where we had to go back and put a vein graft on the circumflex. So I think these techniques work very, very well.

Long term, one of the questions with spasm is bypassing the correct vessel with the correct amount of proximal disease. Early on we were not so focused on that, and I think that probably explains some of our graft failures. More recently, we have really restricted the use of the radial artery to patients with proximal stenoses of greater than $80 \%$.

And your last question about what graft do we really prefer, a lot depends on the comfort level of the surgeon and the patient profile. We have become extremely comfortable with the radial artery and think it is a great conduit as an alternative to the RITA. With so many of our patients being obese and diabetic, we believe these patients benefit by avoiding bilateral ITA grafts. It really depends on the right operation for the right patients with the surgeon being most comfortable.

Dr Tatoulis. Thank you.
Dr Antonio Laudito (Duluth, Minn). I want to thank you for your effort, but I am very concerned because your study started with the acceptance of $5 \%$ utilization of bilateral mammary use in CABG, because if we take this approach, we have also only $35 \%$ performance of mitral valve repair. That does not mean that we give up the mitral valve. The ability to appreciate the BITA value is due to skeletonization and use in situ. If you use the RITA as a free graft, you lose the benefit. Of course, with the radial where you are a master, from your experience, you are achieving the same results. But the BITA patient in situ use and skeletonized, as you can see from the series from Tohru Asai from Japan (the Japanese are examples in the world) and from our own series in the United States with Dr Puskas, even in diabetics, even in fat people, in proper hands achieve the best result in arterial revascularization. We need to open our eyes and accept that it requires time, it is not the usual quick CABG, and is a different quality of revascularization. But this will cancel redo coronary surgery. I think, following the spirit of this organization and what our president said yesterday, we should push and support, despite the difficulties, what is the best for our patients.

Dr Tranbaugh. There is no doubt we need to do more arterial grafting. We do not have any experience with skeletonization. We are well aware of the data and publications, and it certainly may be of significant benefit to patients.

Dr John Puskas (Atlanta, Ga). Dr Tranbaugh, I congratulate you on a well and vigorously conducted trial and study. I have real concern, though, about the end points of stroke and sternal wound infection because I think it makes a great deal of difference how we do this operation, whether it be a BITA or whether it be a radial artery. I would echo concern of using the RITA as a free graft. It is a far more effective conduit as an in situ conduit. I think the clamp on the aorta is a likely explanation for that higher stroke rate in the BITA patient population. Sternal wound infection is indeed a more frequent complication with BITA harvest than with SITA harvest, but, again, it matters how you do it.

I think it matters what the patient's hemoglobin A1c is preoperatively, and I think it matters a great deal how we open the chest, how we harvest that ITA as a skeletonized conduit, and how we close the chest. Those things have a very major impact on morbidity. But we do know that BITA grafting has a very significant impact on long-term survival in comparison with SITA grafting.

The histology of the radial artery is strikingly different from the histology and physiology of the IMA. How do you explain physiologically the conclusion you have reached from this clinical observation study?

Thank you for your analysis.

Dr Tranbaugh. Let me just go back for 1 second. The issue of the free graft versus the in situ graft was not addressed, but certainly Dr Tatoulis has shown that the patencies are identical for those 2 strategies.

The stroke rate was unrelated to the conduit that we chose, and I just wanted to re-emphasize that. And as far as the histology and the biochemical aspects and the physiology of the different grafts, it is hard to speculate as to exactly how that translates into patencies.

I think the take-home message is that we are not doing enough arterial grafting. In the United States it has really been stuck at 5\%, 
and even in the major BITA centers it is only $20 \%$ to $25 \%$ BITA use. We have increased our radial use in the past several years to $70 \%$ to $80 \%$, and year to date this year we have done $90 \%$ of patients with the radial artery. So I think there is an opportunity to do more arterial grafting, and, when properly harvested and deployed, the radial artery works extremely well, has excellent patency, is equivalent to the RITA, and is a whole lot better than vein grafts.

Dr Xin Chen (Nanjing, China). In China, our studies show in diabetic patients the radial artery has more chance to get atherosclerotic lesions. Have you noticed that in the US patients? The second question is, I noticed from your slides there is a big difference between the pump time of the RITA and radial. What is the main reason for that? Is there any technical issue or something else?

Thank you.
Dr Tranbaugh. I will answer your last question first. The pump time differences were primarily because Beth Israel surgeons did both proximals and distals using a single cross-clamp, the St. Luke's surgeons used a partial occluding clamp for the proximals. They also used a lot of sequential grafting, that just took extra time. So the perfusion differences were really related to the technique.

Radial arteries in diabetics can be calcified, and it is usually a diffuse calcification. We have occasionally used those grafts just because there have not been any other grafts available, and they function well. They are sometimes a little difficult to deal with and drive the needle through the areas of calcification, but it seems those grafts actually function well. They are not prone to spasm, they are so rigid that they cannot go into spasm. So, occasionally, we have used those grafts in diabetics. 